\title{
Abertura do Arco MIG do Alumínio
}

\author{
(Arc Initiation in Aluminum GMAW)
}

\author{
Túlio Fernandes dos Santos ${ }^{1}$, Jair Carlos Dutra ${ }^{2}$ \\ ${ }^{1}$ Petrobras - Petroleo Brasileiro SA, UN-ES/ENGP/EMI, Vitória, ES, Brasil, tuliofd@petriobras.com.br \\ ${ }^{2}$ Universidade Federal de Santa Catarina, Departamento de Engenharia Mecânica, Laboratório de Soldagem - LABSOLDA, \\ Florianópolis, SC,Brasil, jdutra@labsolda.ufsc.br
}

\begin{abstract}
Resumo
A utilização de corrente pulsada para a soldagem MIG do alumínio, apesar de ser uma das tecnologias mais indicadas, em virtude de proporcionar melhores resultados, apresenta dificuldades no início do processo, principalmente no que concerne à abertura do arco. Visando desenvolver um processo mais adequado de abertura do arco, foram estudadas duas novas técnicas: a primeira baseada na imposição de elevada corrente, combinada à interrupção do avanço do arame, e uma segunda, com aplicação de baixa corrente, associada ao recuo do arame, que demandou o aperfeiçoamento do cabeçote alimentador de arame. A primeira técnica, apesar de assegurar a ignição do arco, resultou em duas formas de abertura condicionadas à geometria da ponta do arame. Uma delas é explosiva com ignição próxima ao comprimento médio do arame eletrodo, e outra suave com ignição próxima ao ponto de contado do arame eletrodo com o metal de base. A segunda técnica, independentemente da geometria da ponta do arame, promoveu abertura suave, com baixo aporte térmico e ignição do arco sempre próxima ao ponto de contado do arame eletrodo com o metal de base, sendo considerada mais adequada que a primeira.
\end{abstract}

Palavras-chave: MIG; alumínio; abertura do arco; comprimento do arco; ignição do arco.

Abstract: The use of pulsed current in aluminum Gas Metal Arc Welding (GMAW-P), despite to be one of the most indicated technology for providing excellent results, it presents serious arc starting problems, sometimes resulting in starting arc process failure. In order to develop a guaranteed arc initiation process, two techniques were considered and examined: the first using high current level associated to wire feed stopping, and a second using low current level associated to wire return, to which a wire feeder development was carried out. Conditioned by the wire tip geometry the first technique, although assures the arc initiation, it is obtained by two different ways, an exploded ignition close to the wire middle length, or a soft ignition close to the wire tip contact with work piece. The second technique, for any wire tip geometry, assured soft arc ignition, low heat input and ignition always close to the wire tip contact with work piece, being considered more appropriate than the first.

Key-words: GMAW; aluminum; arc initiation; arc length; arc start-up phase, arc striking, arc ignition cycle.

\section{Introdução}

Considerando a importância tecnológica do alumínio e a expansão de seu uso, o aprimoramento das técnicas de soldagem utilizadas para este material, tanto em soldas de acabamento como estruturais, é de fundamental importância em diversos setores da indústria, tais como o aeroespacial e a indústria de transportes.

A soldagem MIG do alumínio apresenta alguns aspectos particulares que dificultam sua operacionalização, dentre os quais está a abertura do arco, em virtude das características físicas deste metal. Convencionalmente a ignição do arco, no processo MIG, é baseada no aquecimento provocado pelo curto circuito estabelecido entre arame eletrodo e o metal de base, porém, o alumínio por possuir uma baixa resistividade elétrica e elevada

(Recebido em 14/09/2008; Texto Final em 30/04/2009). condutibilidade térmica, reduz e dissipa significativamente o calor gerado por efeito joule. Esta condição, aliada à elevada ductilidade do alumínio, dificulta a abertura do arco.

Fontes convencionais de soldagem MIG têm como característica o comando de tensão. Este fato permite que a corrente atinja valores elevados no momento do curto circuito, o que facilita a abertura do arco, porém, mesmo garantindo a abertura, o sistema não é repetitivo.

Farson et al. [1], apresentaram um estudo do processo de abertura do arco MIG para o aço, com fonte de tensão constante, enfocando a influência da geometria da ponta do arame eletrodo. Foram verificados dois tipos característicos de abertura, a explosiva e a suave. A explosiva ocorre quando a ignição se dá no comprimento médio do arame eletrodo e a suave, quando a ignição ocorre a partir do ponto de contato do arame eletrodo com o metal de base. A abertura suave demanda uma menor energia, e é mais provável de ocorrer quando a ponta do arame é cortada e usando-se uma baixa velocidade de aproximação do 
arame.

Estudos conduzidos por Rehfeldt et al. [2] sobre o processo de abertura do arco MIG para o alumínio, realizados com filmagem de alta velocidade, indicam que o arame eletrodo, após movimento de aproximação, flamba devido à colisão contra o metal de base e a continuidade de avanço do arame imposta pelo alimentador. Este fenômeno também foi previsto e verificado para o aço, conforme apresentado por Zhu et al. [3].

Os experimentos de Rehfeldt et al. [2] foram realizados apenas com fontes de tensão constante e ponta do arame cortada, tendo sido verificado que logo após a ignição do arco, ocorrida próximo ao ponto de contato com o metal de base, o arco voltaico pode saltar para o ponto de dobramento do arame eletrodo próximo ao bico de contato, após o que, a extremidade dobrada do arame, sob a influência de forças eletromagnéticas é destacada e expelida para fora da região do arco, resultando em um arco alto, estabelecido próximo ao bico de contato, conforme esquema apresentado na Figura 1.

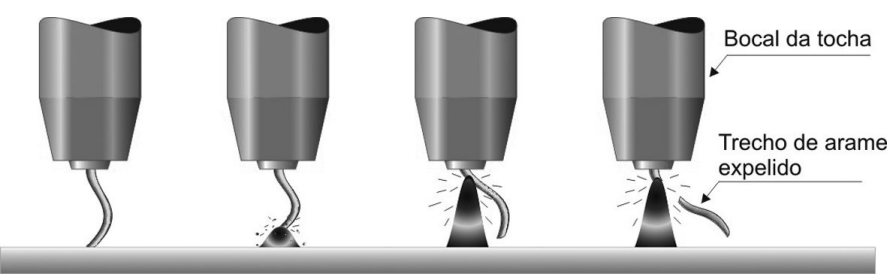

Figura 1. Esquema da abertura do arco com ejeção da extremidade do arame conforme Rehfeldt et al. [2].

As conclusões apresentadas por Farson et al. [1] e Rehfeldt et al. [2], são de significativa importância, porém não contemplam o uso de fontes com imposição de corrente nem a utilização de sistemas de controle capazes de monitorar as condições e regular variáveis durante o processo de abertura.

Para a soldagem do alumínio, a utilização de fontes com imposição de corrente é considerada como adequada, tendo em vista o uso da corrente pulsada, entretanto, a simples imposição de corrente, sem qualquer tipo de controle durante o processo, tornaria a abertura do arco tarefa difícil.

O principal método de controle para a abertura do arco MIG em fontes de soldagem por imposição de corrente é similar ao das fontes de soldagem por comando de tensão, principalmente devido à sua simplicidade, sendo que no momento em que ocorre o contato entre arame eletrodo e metal de base, a fonte é comandada a impor níveis elevados de corrente, produzindo o calor necessário para a abertura do arco voltaico, porém apresenta os mesmos problemas de repetibilidade verificados com fontes de soldagem por comando de tensão.

O presente trabalho está focado no desenvolvimento do processo e de equipamentos que favoreçam a abertura do arco com fontes de corrente, tendo sido conduzidos experimentos para estudar duas técnicas de abertura de arco: uma utilizando elevados níveis de corrente e outra, utilizando baixos níveis de corrente associada ao retorno do arame.

A primeira técnica estudada, utilizando elevados níveis de corrente, foi combinada à interrupção do avanço do arame, como proposto por Santos [4], de forma a minimizar os problemas decorrentes da flambagem do arame no momento do contato com o metal de base, como relatado por Rehfeldt et al. [2], para o que foi desenvolvido um sistema de controle capaz de interromper a alimentação de arame quando da ocorrência do contato deste com o metal de base.

A segunda técnica estudada foi baseada na combinação de baixos níveis de corrente ao movimento de retorno do arame eletrodo, similar ao processo de abertura do arco TIG denominado lift-arc, e demandou o desenvolvimento de um novo cabeçote alimentador de arame, com sistema controlado de retorno do arame durante o processo de abertura do arco.

\section{Procedimentos Experimentais}

\subsection{Aspectos gerais dos experimentos.}

Nos experimentos do presente trabalho foram utilizadas chapas de alumínio $1200 \mathrm{H} 14$, com espessura de $3 \mathrm{~mm}$, arame ER 4043 de 1,2 mm de diâmetro e gás de proteção Argônio com vazão de $15 \mathrm{l} / \mathrm{min}$.

A máquina de solda utilizada foi uma fonte multiprocesso transistorizada, modelo Inversal 300 com cabeçote de alimentação modelo STA20 equipado com sistema de controle de retorno, de fabricação da IMC.

Para controle da fonte de soldagem, foi utilizado microcomputador equipado com placa para aquisição e controle. Para monitoração da soldagem, utilizou-se o sistema de aquisição com freqüência de $5 \mathrm{kHz}$, equipado com sensores de corrente, tensão e velocidade de arame.

A preparação da ponta do arame foi feita por dois processos, um cortando-se a ponta com alicate de corte diagonal, conforme Figura 2a, outro deixando a ponta arredondada, com diâmetro de aproximadamente $1,5 \mathrm{~mm}$, como resultado aleatório após a interrupção de arco, conforme Figura 2b.

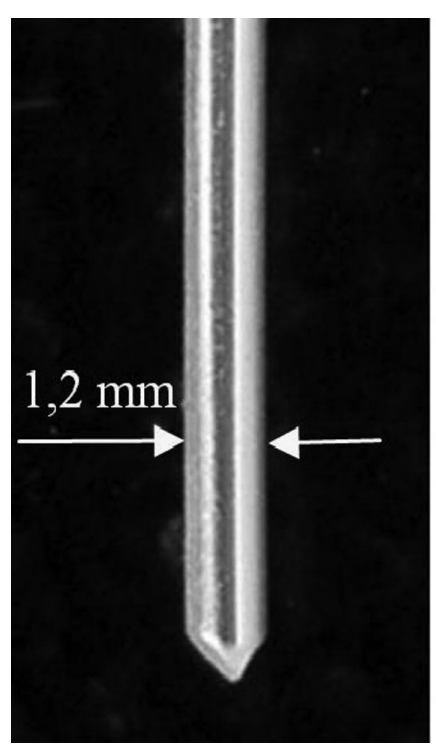

(a)

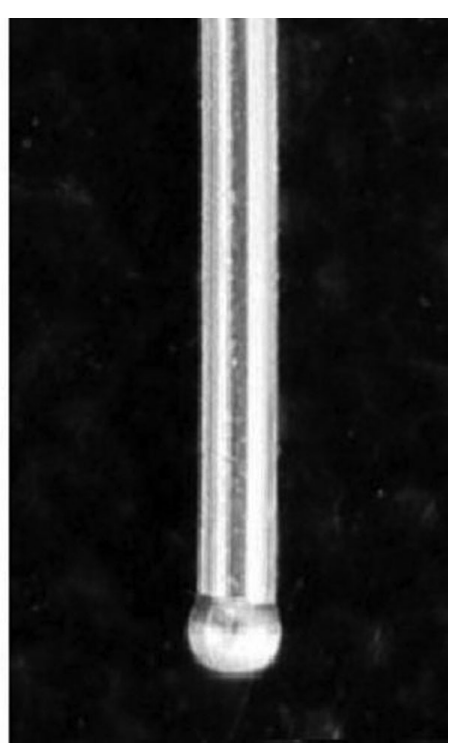

(b)
Figura 2. Tipos de geometria da ponta do arame: Cortada (a) e Arredondada (b). 


\subsection{Procedimentos para abertura do arco com corrente elevada}

A fim de identificar a influência da geometria da ponta do arame, da corrente de abertura e da velocidade de aproximação do arame nas condições de abertura do arco, foram realizados experimentos de abertura do arco, combinando variações dos três fatores em um projeto experimental fatorial $(2 \mathrm{k})$ conforme Tabela 1.

Os parâmetros utilizados para o nível alto e baixo do projeto fatorial foram selecionados considerando que:

- A corrente nominal máxima disponível no equipamento utilizado é de $450 \mathrm{~A}$, optando-se por utilizar como nível alto de corrente de abertura o valor de $440 \mathrm{~A}$, próximo ao limite do equipamento e como nível baixo o valor de 340 A, estabelecendo uma diferença de 100 A entre os níveis considerados.

- A velocidade do arame mínima disponível no sistema de alimentação é de $1 \mathrm{~m} / \mathrm{min}$, valor estabelecido como o nível baixo para a velocidade do arame durante a aproximação. $\mathrm{O}$ nível alto foi estabelecido como $3 \mathrm{~m} / \mathrm{min}$, compatível com faixa operacional de 70 A para o processo MIG Pulsado do Alumínio com o arame utilizado.

- A geometria da Ponta é geralmente estabelecida pelo operador, que corta a ponta do arame com alicate, ponta Cortada, ou deixa como finalizada em soldagem anterior, com a ponta Arredondada.

Tabela 1. Dados para experimentos de abertura com corrente elevada.

\begin{tabular}{c|c|c}
\hline Fatores & Descrição & Valores utilizados \\
\hline $\mathrm{I}(\mathrm{A})$ & Corrente de Abertura & 340 ou $440 \mathrm{~A}$ \\
\hline $\mathrm{Va}(\mathrm{m} / \mathrm{min})$ & Velocidade de aproximação do Arame & $1 \mathrm{ou} 3 \mathrm{~m} / \mathrm{min}$ \\
\hline Geometria da Ponta & Formato da extremidade do arame & Arredondada ou Cortada \\
\hline
\end{tabular}
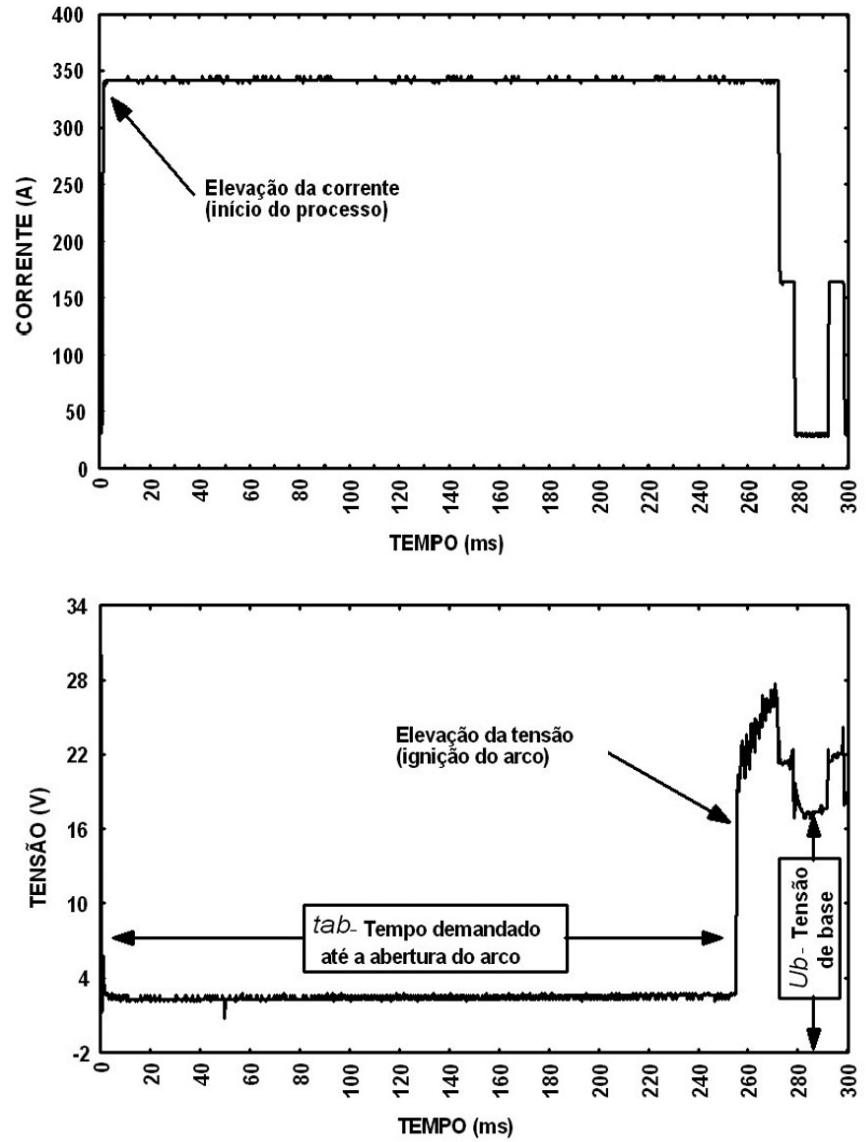

Figura 3. Oscilogramas de Corrente e Tensão (abertura com correntes elevadas).

Nestes experimentos o comando da fonte de soldagem foi efetuado via microcomputador, através do programa, que, alimentado com as informações de velocidade de aproximação do arame, corrente a ser imposta no momento do curto-circuito,

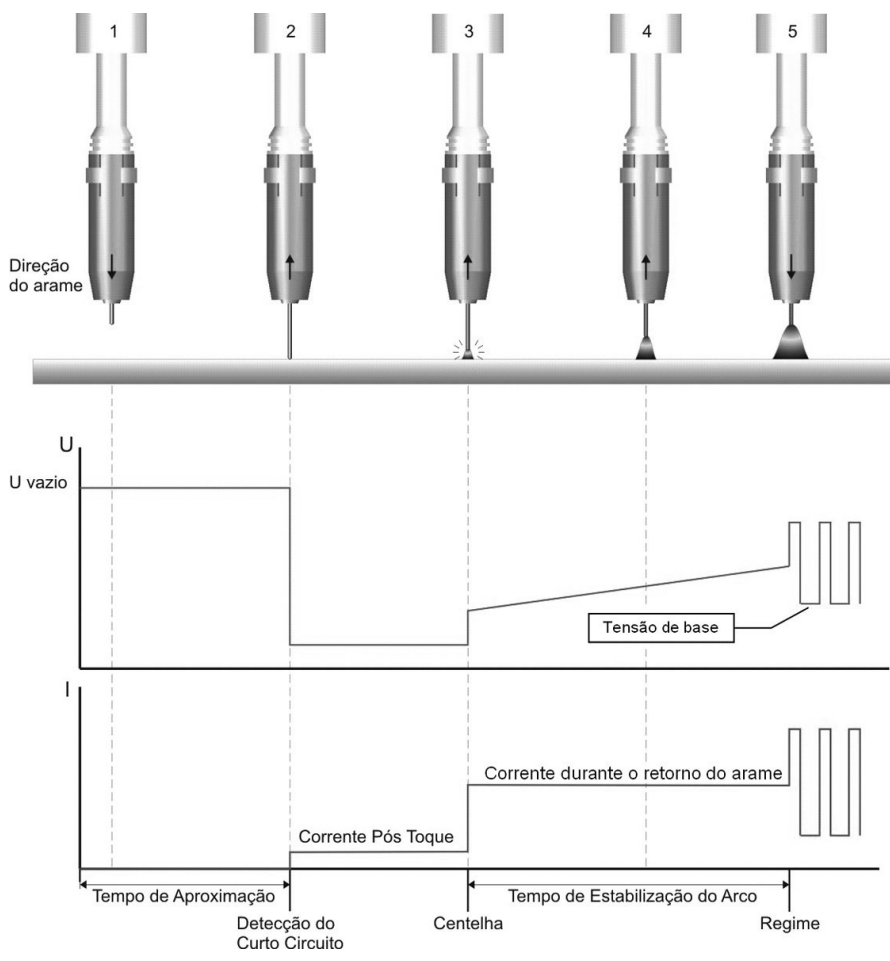

Figura 4. Esquema da abertura do arco com retorno do arame.

e tensão de identificação da condição de abertura do arco, comandava a fonte de soldagem monitorando a corrente e a tensão durante a abertura, seguindo a rotina abaixo:

- Avançar arame com a velocidade de aproximação especificada (1 e $3 \mathrm{~m} / \mathrm{min}$ );

- Interromper a alimentação do arame após detectar corrente superior a $5 \mathrm{~A}$;

- Impor corrente de abertura especificada (340 e 440 A);

- Após identificar nível de tensão superior a $30 \mathrm{~V}$, passar para a 
fase de regime, com corrente pulsada e velocidade de arame de regime.

O comando de interrupção da alimentação do arame evita que o arame se embole, após tocar o metal base, caso não ocorra a imediata abertura do arco, possibilitando a realização de experimentos com correntes de abertura relativamente baixas e geometrias de ponta do arame desfavoráveis à abertura.

Para identificar a influência dos fatores considerados, geometria da ponta do arame, corrente de abertura e velocidade de aproximação do arame, nas condições de abertura do arco, os oscilogramas de tensão e corrente de cada ensaio realizado, foram analisados e identificado o instante em que ocorre a ignição do arco, caracterizado pela súbita elevação da tensão, conforme Figura 3. Com base nos oscilogramas foram verificados os seguintes aspectos do processo de abertura:

- tab : tempo demandado até a abertura, caracterizada pela elevação da tensão (Figura 3);

- Eaa : energia demandada até a abertura do arco;

- Ub : tensão de base imediatamente após a abertura (Figura 3).

\subsection{Procedimentos para abertura do arco com correntes baixas e retorno do arame.}

Visando desenvolver uma técnica que assegurasse a repetibilidade do processo de abertura suave do arco, ou seja, que a abertura ocorresse sempre no ponto de contato do arame eletrodo com o metal de base e não demandasse elevados níveis de corrente de abertura, foi elaborada uma nova técnica de abertura do arco, utilizando o retorno controlado do arame.

A abertura do arco com retorno do arame foi concebida com a rotina de avançar o arame até tocar no metal de base, e, após o contado, comandar simultaneamente o retorno do arame e a aplicação de baixo nível de corrente, suficiente para manter o arco voltaico até que fosse atingido o comprimento de arco desejado, finalizando a fase de abertura de arco e passando o processo para o regime de soldagem, conforme esquema apresentado na Figura 4.

A Figura 4 apresenta quatro intervalos, indicados entre as cinco representações de tocha (1,2,3,4 e 5), sendo:

- Aproximação do arame: identificado pela tensão em vazio e corrente nula.

- Curto circuito: identificado pela tensão próxima a zero e corrente próxima a $10 \mathrm{~A}$ (a corrente foi limitada pelo sistema para evitar a adesão da ponta do arame ao metal de base).

- Retorno do arame com arco aberto: identificada pela rampa de tensão, decorrente do afastamento progressivo do arame, e pelo patamar de corrente.

- Regime de soldagem: identificado pela forma de onda de corrente pulsada.

Após desenvolvido um novo cabeçote alimentador, com circuito de controle do retorno do arame, foram realizados experimentos com fonte de corrente, usando a rotina proposta, com monitoração da tensão, corrente e velocidade do arame.

Considerando que a técnica de abertura proposta estabelece um novo intervalo marcado pelo movimento de retorno do arame, buscou-se avaliar, além da influência da geometria da ponta do arame, a influência das variáveis: corrente, duração e velocidade do arame, durante o intervalo com arame em movimento de retorno. Os experimentos foram conduzidos, combinando variações de quatro fatores em um projeto experimental fatorial (2k) conforme Tabela 2.

\section{ANÁLISE DOS EXPERIMENTOS}

\subsection{Análise de experimentos - Abertura do arco com corrente elevada}

Os resultados dos experimentos de abertura com corrente elevada estão apresentados na Tabela 3.

Tabela 2. Dados para experimentos de abertura com corrente baixa e retorno do arame.

\begin{tabular}{c|c|c}
\hline Fatores & Descrição & Valores utilizados \\
\hline I ret $(\mathrm{A})$ & Corrente durante o retorno do arame & 50 ou $100 \mathrm{~A}$ \\
\hline t ret $(\mathrm{ms})$ & Tempo de retorno do arame & $50 \mathrm{ou} 100 \mathrm{~ms}$ \\
\hline Va ret $(\mathrm{m} / \mathrm{min})$ & Velocidade do arame no retorno & $1 \mathrm{ou} 2 \mathrm{~m} / \mathrm{min}$ \\
\hline Geometria da Ponta & Formato da extremidade do arame & Arredondada ou cortada \\
\hline
\end{tabular}

Tabela 3. Resultados do conjunto principal de experimentos de abertura.

\begin{tabular}{c|c|c|c|c|c|c}
\hline $\begin{array}{c}\text { Código do } \\
\text { experimento }\end{array}$ & $\mathrm{I}(\mathrm{A})$ & $\mathrm{Va}(\mathrm{m} / \mathrm{min})$ & Geometria da Ponta & $\begin{array}{c}\mathrm{t}_{\mathrm{ab}} \\
(\mathrm{ms})\end{array}$ & $\begin{array}{c}\mathrm{E}_{\mathrm{aa}} \\
(\mathrm{J})\end{array}$ & $\begin{array}{c}\mathrm{U}_{\mathrm{b}} \\
(\mathrm{V})\end{array}$ \\
\hline $\mathrm{A} 3411$ & 340 & 1 & Cortada & 0,5 & 0,47 & 16,8 \\
\hline $\mathrm{B} 3411$ & 340 & 1 & Cortada & 0,8 & 0,08 & 16,3 \\
\hline $\mathrm{C} 3411$ & 340 & 1 & Cortada & 1 & 0,09 & 17 \\
\hline $\mathrm{D} 3411$ & 340 & 1 & Cortada & 1,3 & 0,15 & 15,8 \\
\hline $\mathrm{A} 3410$ & 340 & 1 & ARREDONDADA & 317 & 411,47 & 18 \\
\hline $\mathrm{B} 3410$ & 340 & 1 & ARREDONDADA & 322,4 & 376,89 & 18,8 \\
\hline $\mathrm{C} 3410$ & 340 & 1 & ARREDONDADA & 297,6 & 236,89 & 19,5 \\
\hline
\end{tabular}




\begin{tabular}{c|c|c|c|c|c|c}
\hline D3410 & 340 & 1 & ARREDONDADA & 292,6 & 266,27 & 17 \\
\hline A3431 & 340 & 3 & Cortada & 0,8 & 0,26 & 16 \\
\hline B3431 & 340 & 3 & Cortada & 3 & 2,93 & 16,8 \\
\hline C3431 & 340 & 3 & Cortada & 0,6 & 0,03 & 17,3 \\
\hline D3431 & 340 & 3 & Cortada & 1,4 & 0,80 & 16,8 \\
\hline A3430 & 340 & 3 & ARREDONDADA & 263,6 & 286,53 & 18 \\
\hline B3430 & 340 & 3 & ARREDONDADA & 276,8 & 417,41 & 19 \\
\hline C3430 & 340 & 3 & ARREDONDADA & 300,5 & 518,96 & 17 \\
\hline D3430 & 340 & 3 & ARREDONDADA & 286,8 & 267,01 & 20 \\
\hline A4411 & 440 & 1 & Cortada & 0,9 & 0,78 & 15,5 \\
\hline B4411 & 440 & 1 & Cortada & 0,6 & 0,38 & 16 \\
\hline C4411 & 440 & 1 & Cortada & 0,4 & 0,02 & 16,8 \\
\hline D4411 & 440 & 1 & Cortada & 1,2 & 0,63 & 17 \\
\hline A4410 & 440 & 1 & ARREDONDADA & 201 & 589,33 & 19,8 \\
\hline B4410 & 440 & 1 & ARREDONDADA & 183,4 & 472,44 & 17,5 \\
\hline C4410 & 440 & 1 & ARREDONDADA & 196,8 & 318,62 & 18 \\
\hline D4410 & 440 & 1 & ARREDONDADA & 188,8 & 461,05 & 18,3 \\
\hline A4431 & 440 & 3 & Cortada & 0,8 & 0,05 & 15,5 \\
\hline D4431 & 440 & 3 & Cortada & 2,4 & 0,12 & 16,5 \\
\hline E4431 & 440 & 3 & Cortada & 2,4 & 1,22 & 16,3 \\
\hline F4431 & 440 & 3 & Cortada & 1 & 0,54 & 16,6 \\
\hline A4430 & 440 & 3 & ARREDONDADA & 198,2 & 397,39 & 16,5 \\
\hline B4430 & 440 & 3 & ARREDONDADA & 189,6 & 459,78 & 18 \\
\hline C4430 & 440 & 3 & ARREDONDADA & 182,6 & 183,88 & 17,3 \\
\hline D4430 & 440 & 3 & ARREDONDADA & 181 & 209,60 & 16,8 \\
\hline
\end{tabular}

Tabela 4. Quadro demonstrativo de influência dos fatores estudados.

\begin{tabular}{l|l|l|l}
\hline \multicolumn{1}{c|}{ Fatores estudados } & \multicolumn{2}{c}{ Probabilidade de erro Tipo I } \\
\cline { 2 - 4 } & $\mathrm{t}_{\mathrm{ab}}$ & $\mathrm{E}_{\mathrm{aa}}$ & $\mathrm{U}_{\mathrm{b}}$ \\
\hline 1-Velocidade de aproximação do arame & 0,025474 & 0,402630 & 0,439939 \\
\hline 2-Geometria da Ponta & 0,000000 & 0,000000 & 0,000009 \\
\hline 3-Corrente de Abertura Interações dos fatores & 0,000000 & 0,507745 & 0,115235 \\
\hline \multicolumn{1}{|c|}{} & & \\
\hline 1 e 2- Velocidade de aproximação do arame e Geometria da Ponta & 0,015046 & 0,393169 & 0,308684 \\
\hline 1 e 3- Velocidade de aproximação do arame e Corrente de Abertura & 0,091908 & 0,097616 & 0,144860 \\
\hline 2 e 3- Geometria da Ponta e Corrente de Abertura & 0,000000 & 0,507745 & 0,600548 \\
\hline 1 e 2 e 3- Velocidade de aprox. arame, Geom. da Ponta e Corrente de Abertura & 0,101737 & 0,100878 & 0,370482
\end{tabular}

Para caracterizar estatisticamente a influência dos fatores estudados (corrente, geometria da ponta e velocidade de aproximação), bem como de suas interações, sobre as condições de abertura do arco, expressas pelo tempo, energia e tensão após a abertura, foi realizada a análise das variâncias, assumindo o nível de significância de $5 \%$ como satisfatório aos estudos. Na Tabela 4 estão identificados os aspectos que são influenciados pelos fatores estudados, estando sombreadas as combinações de fatores e aspectos da abertura do arco para os quais foi verificada probabilidade de erro do tipo I inferior a 5\%.

Conforme resultados estatísticos, todos os fatores considerados: velocidade de aproximação do arame, geometria da ponta do arame e corrente de abertura, exercem influência sobre o tempo demandado até a abertura do arco $\left(\mathrm{t}_{\mathrm{ab}}\right)$, conforme Figura
5, mas apenas a geometria da ponta do arame exerce influência significativa sobre a energia demandada até a abertura e sobre a tensão de base após a abertura, Figuras 6 e 7 respectivamente.

Conforme apresentado na Figura 5, verifica-se que a geometria da ponta do arame é o fator predominante sobre o tempo demandado para abertura do arco, e que para as condições com geometria da ponta do arame cortada os demais fatores não apresentam influência expressiva. O segundo fator de influência no tempo de abertura do arco é a corrente de abertura, sendo que correntes mais elevadas reduzem o tempo para abertura do arco, embora esta influência seja expressiva apenas para as condições com geometria da ponta arredondada. O efeito da variação da velocidade de aproximação do arame sobre o tempo para abertura é pequeno, mesmo para geometria da ponta arredondada, o que 
aparentemente não condiz com o estudo apresentado por Farson [1], porém deve-se considerar que a redução da influência deste fator é conseqüência do sistema de controle implementado, que interrompe o avanço do arame após o contato com o metal de base.

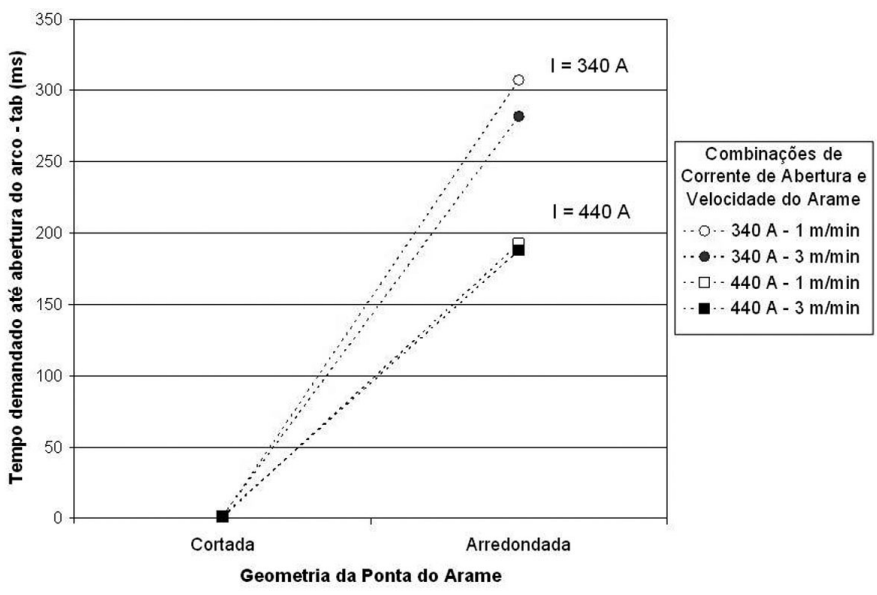

Figura 5. Influencia dos fatores sobre o tempo demandado até a abertura do $\operatorname{arco}, \mathrm{t}_{\mathrm{ab}}(\mathrm{ms})$.

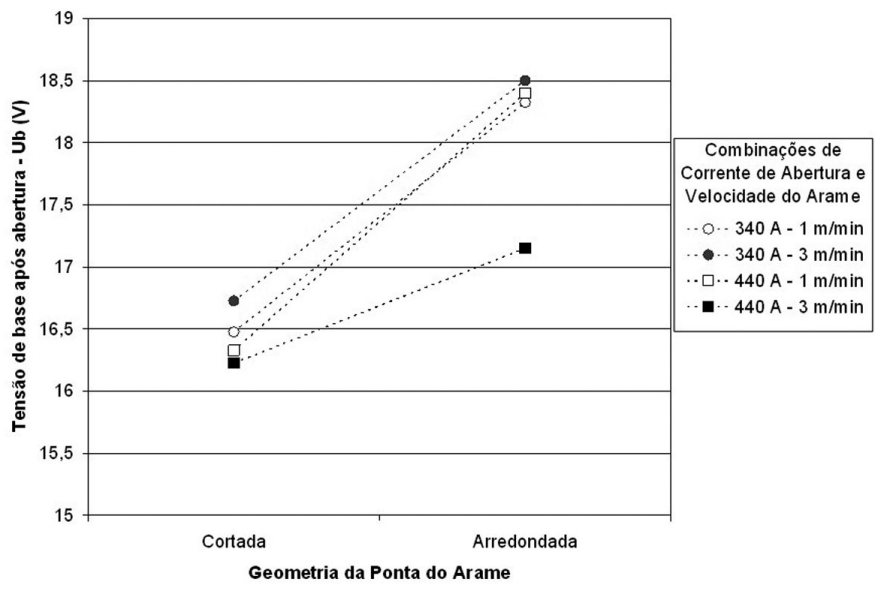

Figura 7. Influencia dos fatores sobre a tensão de base após a abertura do arco, $\mathrm{U}_{\mathrm{b}}(\mathrm{V})$.

A influência da geometria da ponta sobre a energia demandada antes da abertura do arco, Figura 6, confirma os estudos

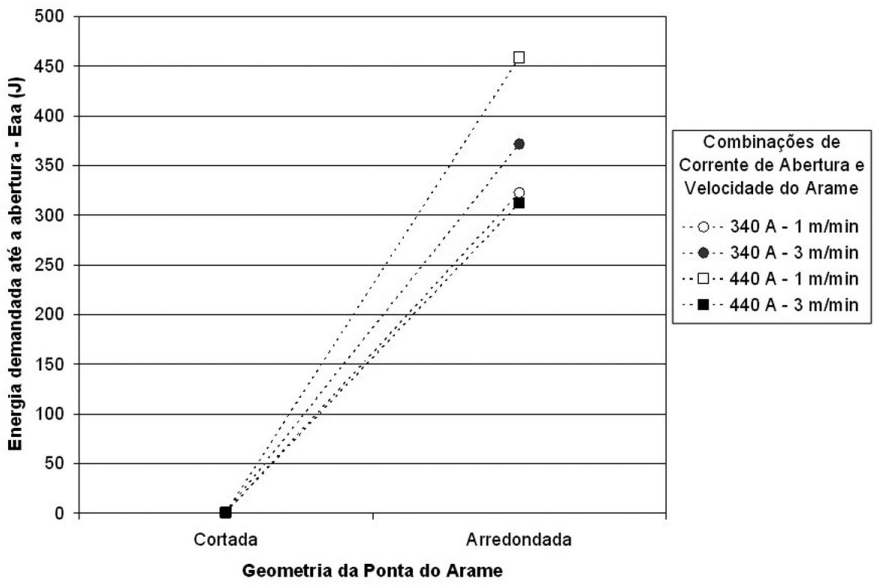

Figura 6. Influencia dos fatores sobre a energia demandada até a abertura do $\operatorname{arco}, \mathrm{E}_{\mathrm{aa}}(\mathrm{J})$.

apresentados por Farson [1], sendo a energia um indicador do tipo de abertura ocorrida, que é suave quando a ponta do arame está cortada, demandando menor energia, e brusca quando está arredondada, demandando maior energia.

A geometria da ponta do arame, conforme Figura 7, exerce significativa influência da sobre a tensão de base após a abertura do arco, que é um indicador do comprimento do arco, sendo verificada uma maior tensão para as condições com a ponta do arame arredondada, o que corresponde a um maior comprimento de arco. Para análise deste comportamento foram realizadas filmagens, nas quais foi verificado que a fragmentação do arame na abertura pode ocorrer, ou na região de contato do arame eletrodo com o metal de base, quando a ponta está cortada, resultando em menor comprimento de arco após a abertura, Figura 8, ou próximo ao comprimento médio do arame eletrodo, quando a ponta deste está arredondada, resultando em maior comprimento de arco, Figura 9.

\subsection{Análise de experimentos - Abertura do arco com baixa corrente e retorno do arame}

Por meio de oscilogramas de corrente e tensão, apresentados nas Figuras 10, 11, 12 e 13 buscou-se fazer uma análise qualitativa da influência dos parâmetros de abertura (I ret, Va ret, t ret e Geometria da Ponta) sobre o comportamento do sistema
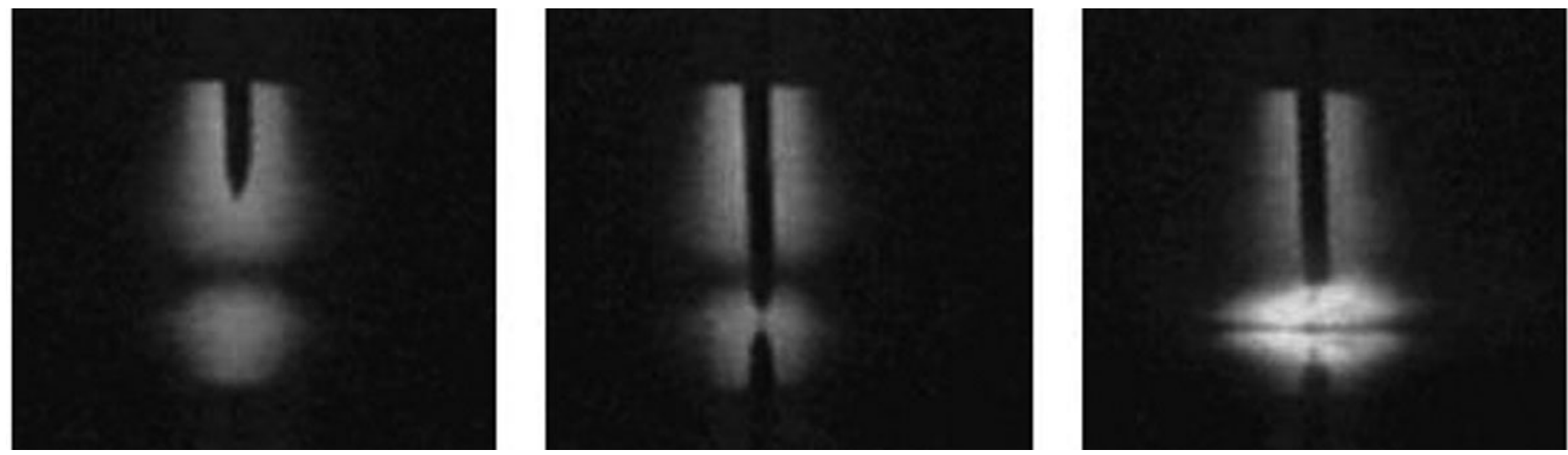

Figura 8. Seqüência da abertura do arco com ponta do arame cortada. 

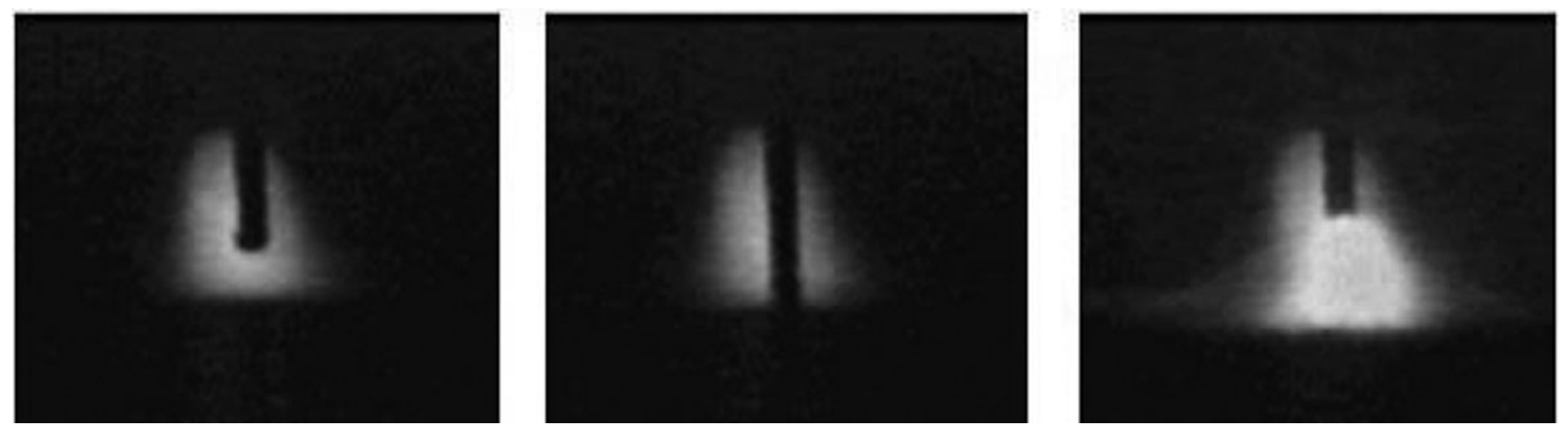

Figura 9. Seqüência da abertura do arco com ponta do arame arredondada.

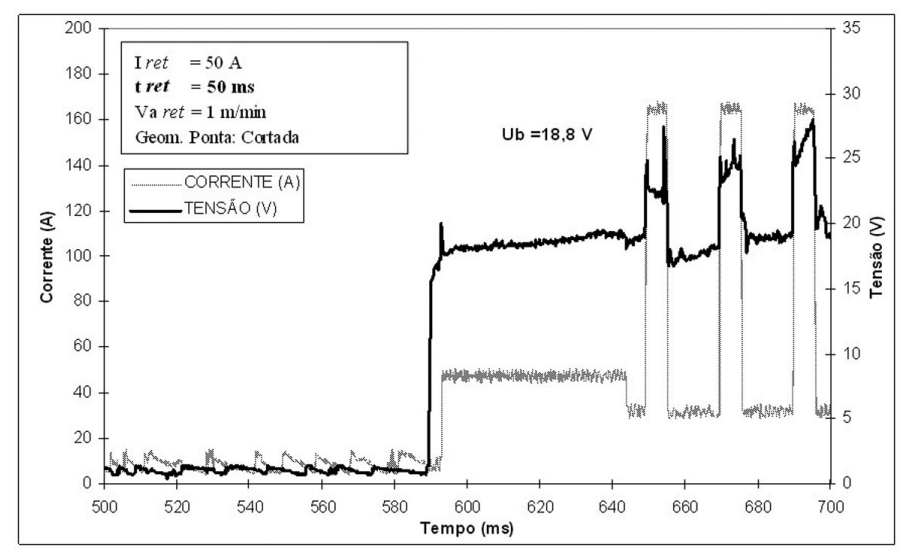

(a)

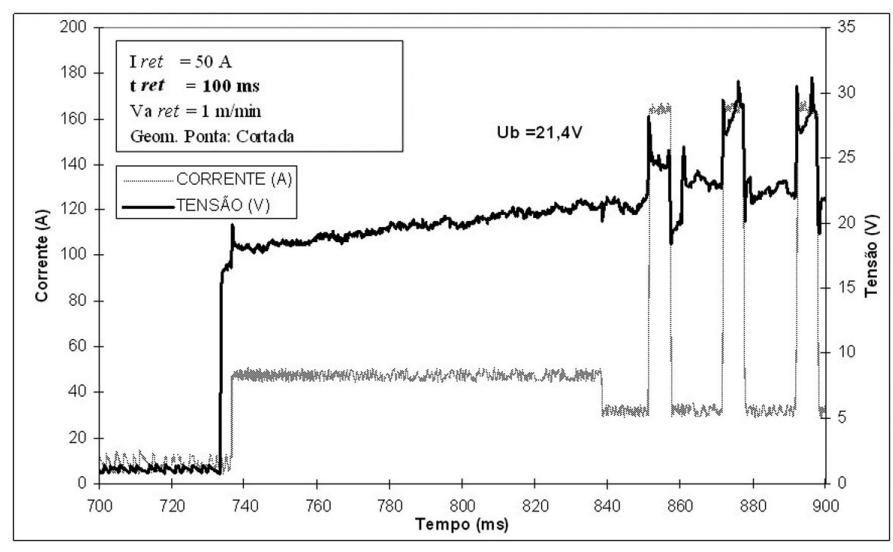

(b)

Figura 10. Oscilogramas de corrente e tensão - Tempo em retorno: 50 ms (a) e 100 ms (b).

proposto, sendo utilizada a tensão de base $\left(\mathrm{U}_{\mathrm{b}}\right)$, imediatamente após o procedimento de abertura, para indicar o comprimento do arco neste instante.

Em experimentos com diferentes tempos de retorno do arame eletrodo (t ret), $50 \mathrm{~ms}$ (Figura 10a) e $100 \mathrm{~ms}$ (Figura 10b), verificou-se que os experimentos com maior tempo de retorno resultaram em maiores níveis de tensão de base $\left(U_{b}\right)$ após a abertura, resultando em que o arco ficasse mais próximo do bico de contato e o regime permanente (corrente pulsada) se iniciasse

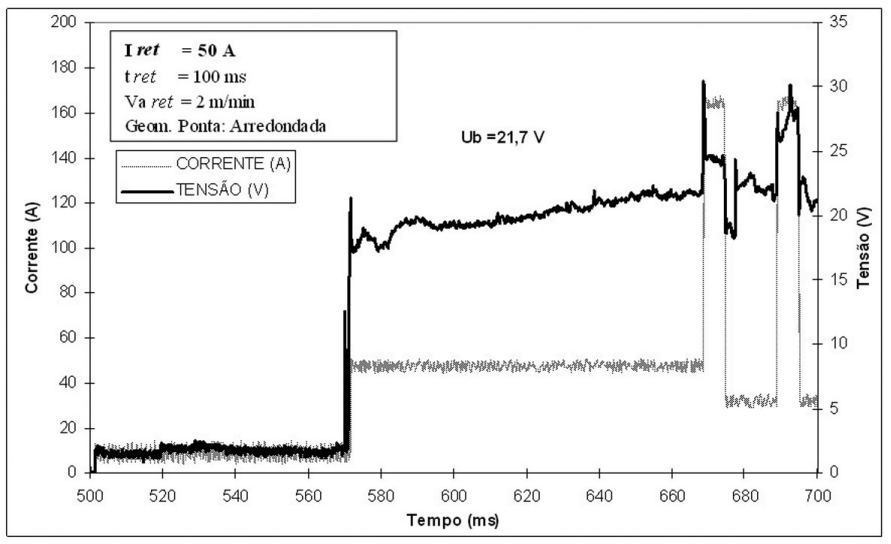

(a) com um maior comprimento de arco.

Efeito similar ao aumento do tempo de retorno do arame (t ret) se observou em experimentos com diferentes níveis de corrente de retorno (I ret), 50 A (Figura 11a) e 100 A (Figura 11b), sendo identificada maior tensão de base $\left(U_{b}\right)$ para condições de maior nível de corrente de retorno, correspondendo ao aumento da taxa de fusão provocada pela corrente mais elevada durante o período de retorno do arame.

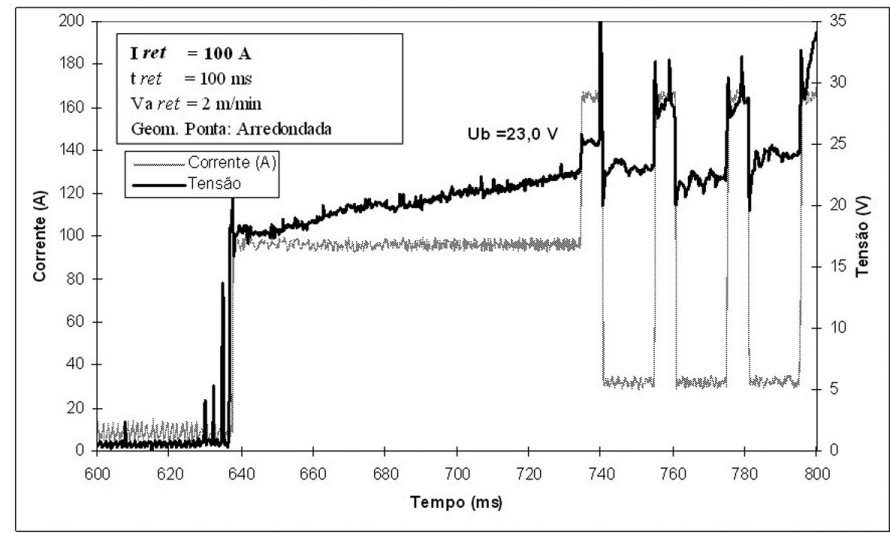

(b)

Figura 11. Oscilogramas de corrente e tensão - Corrente em retorno: 50 A (a) e 100 A (b). 
Nos experimentos com diferentes velocidades de arame no retorno (Va ret), $1 \mathrm{~m} / \mathrm{min}$ (Figura 12a) e $2 \mathrm{~m} / \mathrm{min}$ (Figura 12b), verificou-se um pequeno aumento da tensão de base $\left(\mathrm{U}_{\mathrm{b}}\right)$. Como o sistema de alimentação, ao entrar em movimento, demanda um tempo para atingir a velocidade comandada, deve-se considerar que, para os reduzidos intervalos de tempo de retorno estabelecidos, os ensaios não foram realizados efetivamente com

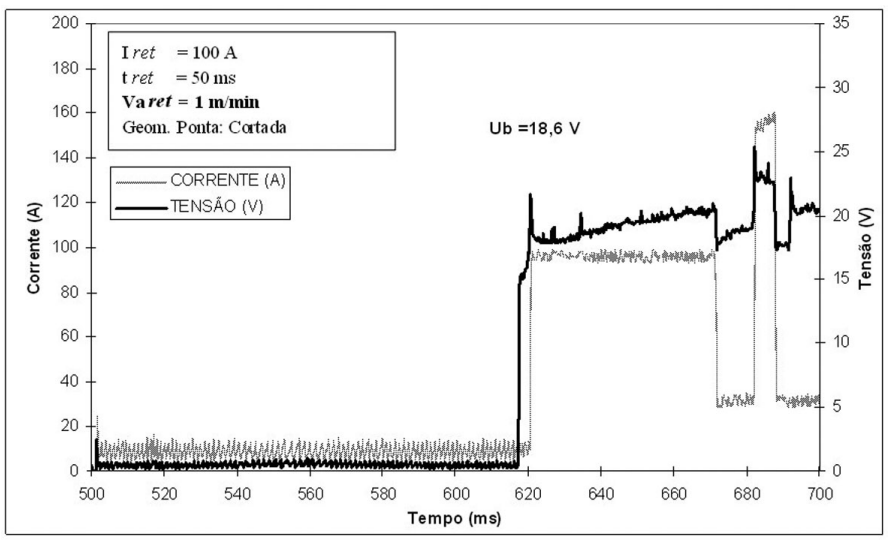

(a) a velocidade prevista, não permitindo abstrair uma conclusão quanto à influência deste fator, entretanto deve-se destacar que para as condições dinâmicas do sistema de alimentação usado, e tempos de retorno de arame estabelecidos, a velocidade de retorno comandada não exerceu influência expressiva quando comparada à influência do tempo de retorno ou da corrente de retorno.

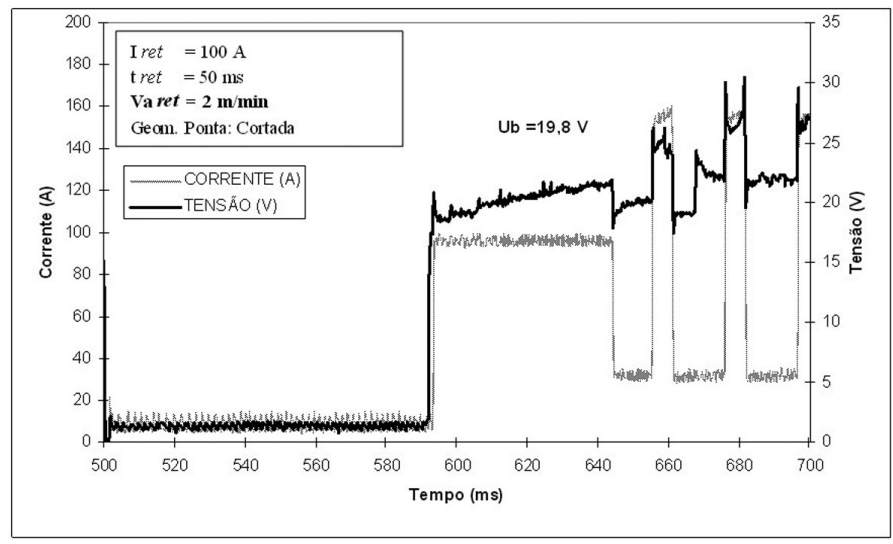

(b)

Figura 12. Oscilogramas de corrente e tensão - Velocidade do arame em retorno: $1 \mathrm{~m} / \mathrm{min}$ (a) e $2 \mathrm{~m} / \mathrm{min}$ (b).

$\mathrm{Na}$ análise realizada sobre os oscilogramas correspondentes à variação apenas da geometria da ponta do arame, Arredondada (Figura 13a) ou Cortada (Figura 13b), observou-se que este fator não influiu de forma significativa nos experimentos. A abertura do arco realizada com retorno do arame fez com que ambas às

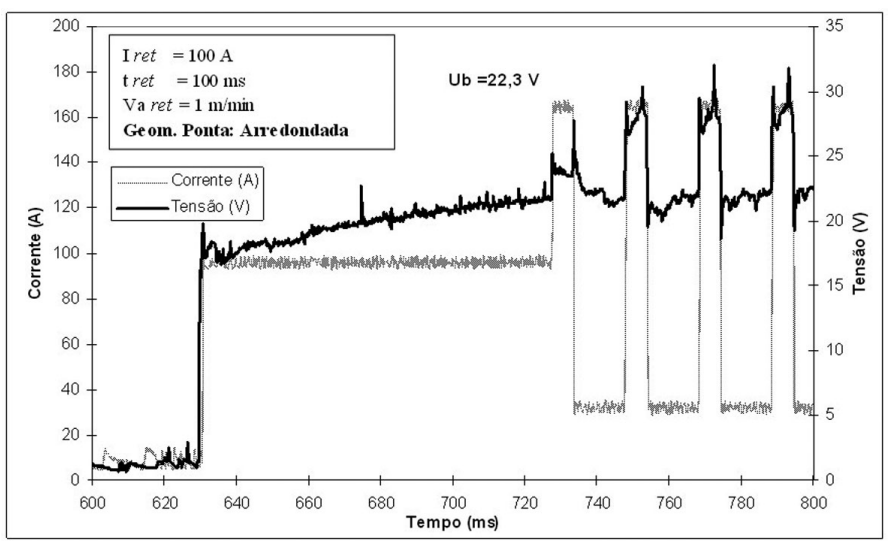

(a) geometrias de ponta (arredondada e cortada) apresentassem resultados muito semelhantes na tensão de base após a abertura $\left(\mathrm{U}_{\mathrm{b}}\right)$, sendo o principal diferencial do sistema proposto em relação à abertura com correntes elevadas.

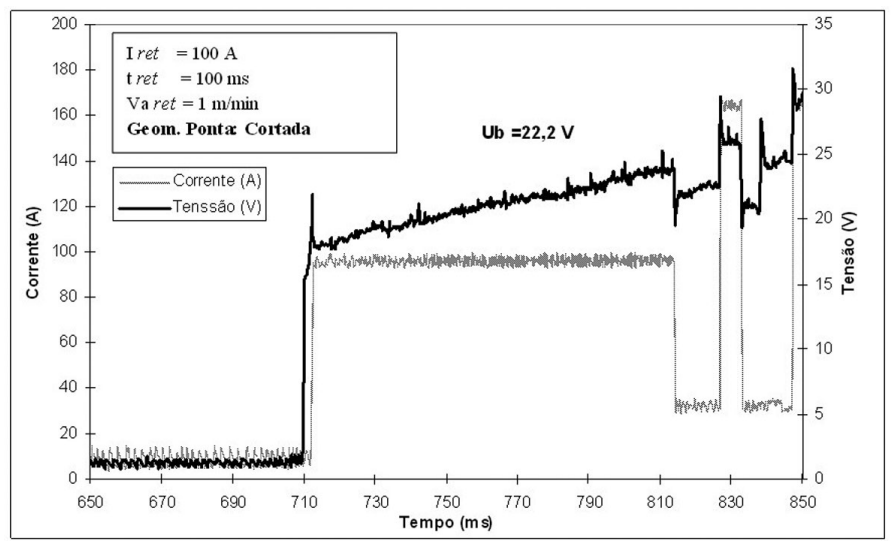

(b)

Figura 13. Oscilogramas de corrente e tensão - Geometria da ponta do arame: Arredondada (a) e Cortada (b).

\section{CONCLUSÕES}

A Primeira técnica proposta para abertura do arco MIG do alumínio, com imposição de elevados níveis de corrente, apesar de promover a abertura do arco, resultou em um processo com diferentes comportamentos, sendo verificada significativa variação do tempo demandado para a abertura, e da tensão do arco após a abertura. O tempo demandado para abertura está condicionado principalmente à geometria da ponta do arame, o que confirma a necessidade do sistema de controle capaz de interromper a alimentação do arame, após a colisão deste contra o metal de base, até que seja verificada a abertura do arco, de forma a evitar que o arame flambe ou se embole no mecanismo tracionador.

A segunda técnica proposta para abertura de arco, utilizando baixos níveis de corrente e retorno do arame, embora demande equipamento com características especiais, assegurou repetibilidade da abertura do arco no ponto de contato entre arame eletrodo e metal de base, assegurando sempre uma abertura suave. Ao contrário do processo de abertura com correntes 
elevadas esta segunda técnica não é afetada pela aleatoriedade da geometria da ponta.

Considerando os resultados obtidos, a primeira técnica proposta, utilizando elevados níveis de corrente de abertura combinado com a interrupção da alimentação do arame, atende aos principais casos práticos de soldagem MIG do alumínio, não sendo necessária preparação da ponta do arame.

A segunda técnica proposta, de abertura com retorno de arame e baixo nível de corrente, mostrou-se mais adequada que a primeira, sendo indicada para condições de soldagem especiais, onde seja necessário assegurar uma suave abertura de arco. Esta técnica também não demanda nenhuma preparação da ponta do arame.

\section{REFERÊNCIAS BIBLIOGRÁFICAS:}

[1] FARSON, D.; CONRARDY, C.; TALKINGTON, J.; BAKER, K.; KERSCHBAUMER, T. and EDUWARDS, P., Arc Initiation in Gas Metal Arc Welding, Welding Journal, USA, v. 77, p.315-321, Aug. 1998.

[2] REHFELDT, D.; BREMER, C., Untersuhungen zum Zündverhalten und zur Proze $\beta$ qualität beim MetallInertgasschweißen von Aluminiumlegierungen, Schweißen und Schneiden, v. 45, H. 1, S. 26-31, Jan. 1993.

[3] ZHU, P.; RADOS, M.; SIMPSON, S. W., Theoretical Predictions of the Start-Up Phase in GMA Welding, Welding Journal, p. 269-274, Jul. 1997.

[4] SANTOS, T.F., Estudo Sobre a Abertura e Estabilidade do Arco MIG na Soldagem do Alumínio. Dissertação (Mestrado em Engenharia Mecânica), Universidade Federal de Santa Catarina - UFSC, 2000. 